\title{
LA IDENTIDAD NACIONAL Y LA RELIGIÓN. UN MARCO ANALITITICO APLICADO AL PAIIS VASCO Y QUEBEC
}

\section{National identity and religion. An analytical framework applied to the Basque Country and Quebec}

\author{
Jose Santiago* \\ * GRESCO-TRANSOC, Universidad Complutense de Madrid \\ jasantiago@cps.ucm.es
}

\section{Palabras clave \\ Identidad nacional Religión Nacionalismo Quebec País Vasco}

\section{Keywords}

National identity Religion Nationalism Quebec Basque Country

\begin{abstract}
Resumen
La falta de una definición legítima y consensuada tanto de la identidad nacional como de la religión dificulta el análisis de la relación de estos dos objetos de estudio. Desde el ámbito de las áreas disciplinares de la sociología de la religión y la teoría del nacionalismo, este artículo persigue elaborar un marco analítico para dar cuenta de esta relación, partiendo de una problematización de ambos conceptos que atiende a sus definiciones y a las rupturas epistemológicas que han permitido repensarlos en nuevos dominios teóricos. Tras ello, se profundiza en dicha relación, prestando atención al papel de la religión histórica como marcador de identidad nacional y a la sacralización de la historia y el territorio nacional que lleva a cabo el nacionalismo para hacer plausible un imaginario de continuidad. Para dar muestras de su potencialidad, este marco analítico se aplicará, desde una perspectiva comparada, al País Vasco y Quebec.
\end{abstract}

\section{Abstract}

The analysis of relationship between national identity and religion is complex because of the lack of a legitimate definition of these two objects of study. From the fields of sociology of religion and theory of nationalism, this article aims to develop an analytical framework to account for this relationship. Firstly, we problematize these two objects of study from their definitions and epistemological breaks that have allowed rethink them in other theoretical domains. Secondly, we deepen these relations, paying attention to the role of historical religion as a marker of national identity and to the role of the sacralization of history and territory that make plausible an imaginary of continuity. To show its potential, this analytical framework will be applied to Quebec and the Basque Country from a comparative perspective.

Santiago, J. (2016). La identidad nacional y la religión. Un marco analítico aplicado al País Vasco y Quebec. Papeles del CEIC, vol. 2016/2, papel 156, CEIC (Centro de Estudios sobre la Identidad Colectiva), Universidad del País Vasco, http://dx.doi.org/10.1387/pceic.16260 
1. IDENTIDAD NACIONAL Y RELIGIÓN: DEFINICIONES Y RUPTURAS EPISTEMOLÓGICAS ${ }^{1}$

La identidad es uno de los conceptos más utilizados en las ciencias sociales en las últimas décadas. Debido a ello ha ido adquiriendo un carácter "polimorfo y bulímico" (Dubar, 2002: 10), convirtiéndose así en una noción difícil de asir. Cuando en una primera aproximación nos centramos en el referente inmediato del individuo, la identidad se nos presenta como una de sus dimensiones centrales. Martuccelli (2007), que da cuenta de ella como uno de los ejes de una gramática sociológica del individuo, nos aproxima a la identidad atendiendo a los dos grandes procesos que representa habitualmente. Por un lado, hace referencia a lo que posibilita la permanencia en el tiempo de un individuo, a lo que hace plausible que, a pesar de los cambios que pueda experimentar, siga siendo el mismo individuo. Por otro lado, la identidad remite a una serie de perfiles sociales y culturales propios de los individuos en las sociedades modernas (Ibíd.: 289). Son estos perfiles los que nos adentran en el terreno de la identidad colectiva, ya que, como señala Pérez-Agote, a pesar de que ésta no tiene soporte más allá del individuo, son los que posibilitan que éste se vea "así mismo como 'siendo' una serie de atributos y 'perteneciendo' a una serie de colectivos" (1986: 78). Estos atributos o rasgos y estas pertenencias pueden ser de diversa indole.

¿Qué caracteriza a la identidad colectiva cuando se declina como identidad nacional? En el libro National Identity, Smith, uno de los más importantes teóricos del nacionalismo, definió sus características fundamentales: territorio histórico o patria; mitos comunes y memorias históricas; cultura pública común de masas; derechos legales y deberes para todos los miembros; economía común con movilidad territorial (1991: 14). No obstante, no es evidente que todas estas características sean propias de la identidad nacional, ya que algunas lo son solo si esta se define exclusivamente a partir de las naciones con Estado. Aquí reside la principal crítica que Guibernau ha dirigido a Smith y a partir de la que ha propuesto su propia definición: "la identidad nacional es un fenómeno moderno de naturaleza fluida y dinámica, por medio del cual

\footnotetext{
${ }^{1}$ Quisiera agradecer los comentarios y sugerencias tanto a los evaluadores como al equipo de edición de Papeles del CEIC, que han permitido mejorar este artículo tanto en contenido como en forma. No obstante, la responsabilidad última es únicamente del autor.
} 
una comunidad que comparte un conjunto particular de características es llevada a la creencia subjetiva de que sus miembros están relacionados ancestralmente" (2004: 134). Como se observa en dicha crítica, la definición de la identidad nacional es deudora de la conceptualización de nación. En este punto hay que señalar la falta de consenso de los teóricos consagrados al estudio de la identidad nacional, lo que provoca en no pocos casos una gran confusión entre este concepto y otros como nación, nacionalidad, nacionalismo, carácter nacional, Estado, etc. Este hecho, y otro aún más relevante, como es dar por sentada la existencia de dicha identidad sin problematizarla, han conducido a Malesevic (2011) a sostener que la identidad nacional es una "quimera", un concepto muy poco asentado que debe ser eludido y sustituido por otros más consolidados como ideología o solidaridad.

Ciertamente la identidad nacional es un concepto difícil de asir tanto para los teóricos del nacionalismo como para los propios actores sociales que participan de ella: "la identidad nacional se ha convertido en una idea tan abstracta y volátil que sus adeptos más extremos (los grupos 'identitarios') no buscan ya ni siquiera definirla" (Kaufmann, 2015: 45). Sin embargo, a pesar de su carácter abstracto, cambiante, etc., lo cierto es que permanece como algo muy sólido. Esto es, en definitiva, lo que se quiere mostrar en este artículo: ¿cómo es posible que la identidad nacional se mantenga sólidamente a lo largo del tiempo? Es decir, al igual que cuando hablamos de identidad individual nos referimos a la permanencia de un individuo a lo largo del tiempo a pesar de sus transformaciones, lo que nos interesa aquí analizar es de qué modo se puede mantener una identidad nacional a pesar de los cambios que haya experimentado a lo largo de la historia. Nuestro punto de partida es considerar que la identidad nacional no es algo dado, sino que es el fruto de una construcción social en la que el nacionalismo desempeña un papel fundamental. Para presentar el argumento nos centraremos en las tres características de las "modalidades fuertes de la identidad", que, siguiendo a Gatti (2007), se concretan en tener un nombre, una historia y un territorio. La identidad nacional, que participa de estas modalidades fuertes, resulta plausible cuando se posee un Nombre y se hace visible en un Territorio diferenciado y en la trama de una Historia (Ibid.: 36). Tratamos en este artículo de analizar las herramientas de las que se sirve el nacionalismo para hacer sólida y 
estable la identidad nacional y el papel que en ello ha desempeñado la religión a la hora de "nombrar", "territorializar" e "historizar".

Para acometer este objetivo, es preciso problematizar previamente la propia categoría de religión, sin darla por sentada. Para ello resulta necesario atender a la sociología de la religión, pues, como ha señalado Hervieu-Léger, "ninguna disciplina sociológica se encuentra confrontada, como lo está la sociología de las religiones, con un objeto cuya existencia está propiamente determinada por la definición que se da del mismo" (1993: 48). Si bien hay muchas definiciones de religión, se pueden agrupar en su mayoría en dos tipos: las sustantivas y las funcionales. La diferencia entre ellas radica en que mientras las primeras limitan la religión dependiendo del contenido de las creencias, las segundas extienden el concepto teniendo en cuenta sus funciones sociales. De ahí que estas definiciones también sean calificadas como exclusivas e inclusivas. Generalmente las definiciones sustantivas limitan el concepto de religión a los sistemas de sentido en los que hay una presencia de seres sobrenaturales y que remiten a la transcendencia. Son, por así decirlo, definiciones de religión de "sentido común", con las que los actores sociales podrían sentirse familiarizados. Conceptualizaciones que han sido movilizadas por muchos sociólogos que no han llevado a cabo la ruptura epistemológica con su objeto de estudio o que se han sentido insatisfechos con los resultados de otras rupturas epistemológicas. Un ejemplo de ello lo ofrece Dobbelaere, quien, en clara conversión de la definición durkheimiana que veremos a continuación, sostiene que la religión es "un sistema unificado de creencias y prácticas relativas a una realidad supraempírica y transcendente que incorpora a todos los que se adhieren a ella al seno de una única comunidad moral" (2008:25).

Frente a las definiciones sustantivas, más o menos explicitadas, algunos teóricos sociales han entendido que la religión es una categoría sobre la que es necesario reflexionar más allá del sentido común de los actores. EI sociólogo que más empeño puso en esta ruptura epistemológica fue Durkheim, para quién la religión es "un sistema de creencias y prácticas relativas a las cosas sagradas, es decir, separadas, interdictas, creencias y prácticas que unen en una misma comunidad moral a todos los que se adhieren a ellas" (1982: 42). Tras sus pasos, muchos otros han reafirmado esta concepción de la religión, como, por ejemplo, Caillois, para quien esta "aparece esencialmente como una fuerza de reunión, de comunión, 
como una fuerza no de dispersión social, sino, por el contrario, si me atrevo a utilizar un neologismo, de sursocialización (supersocialización), en tanto que la presencia de lo sagrado es lo que hace indisoluble una comunidad" (1982: 56). La religión es concebida así como una "metainstitución" que hace posible la vida social. Los contenidos específicos que caracterizan a las religiones históricas (lo sobrenatural, lo divino, el misterio) son algo superficial que no debe ocultar la esencia de la religión: "lo que nos une como comunidad". Maffesoli también concurre con esta forma de entender la religión:

\begin{abstract}
"esa fuerza agregativa que se halla en la base de cualquier tipo de sociedad o de asociación. Se la podría denominar (...) con el término de 'religión', empleando este término para designar lo que nos une como comunidad; se trata menos de un contenido, que es del orden de la fe, que de un continente, es decir, de algo que es matriz común o que sirve de soporte al 'estar juntos'" (1990: 82).
\end{abstract}

Para estos sociólogos, la definición de religión debe atender a la función de religare, de tal modo que cualquier conjunto de creencias y prácticas puede ser concebido como tal si cumple dicha función integradora. Los símbolos religiosos, ya sean totémicos, teístas o laicos, son algo secundario y superficial que ocultan la verdadera esencia que les subyace: lo sagrado como categoría que hace plausible el vínculo social.

Sin embargo, estas definiciones funcionales han sido criticadas por ser demasiado inclusivas y poco discriminatorias. Fruto de la insatisfacción con ellas y también con las definiciones sustantivas, guardianas de la "religión auténtica", Hervieu-Léger (1993) ha propuesto una definición alternativa que nos presenta como una tercera vía. Su ruptura epistemológica parte de lo que considera como la necesaria "desustancialización" definitiva del concepto de religión, la cual no remite ni a creencias ni a prácticas específicas, sino que debe ser entendida como un modo particular de organización y funcionamiento del creer. Es así que señala que lo específico de la religión es el tipo de legitimación aportado en el acto de creer, llegando a sostener que "no hay religión sin que sea invocado, en prueba del acto de creer (y de forma que puede ser explícita, semi-explícita, o enteramente implícita), la autoridad de una tradición" (Ibíd.: 110). De este modo, la invocación al pasado en el acto de creer no es un elemento más de la religión, sino su fundamentación misma: "lo esencial (...) no es el contenido mismo de lo que es creído, sino la invención, la producción imaginaria del vínculo 
que, a través del tiempo, funda la adhesión religiosa de los miembros al grupo que forman y a las convicciones que los vinculan" (Ibíd.: 118). Según este planteamiento, para hablar de religión debemos encontrarnos ante la presencia de tres elementos interrelacionados: la expresión de una creencia, la memoria de una continuidad y la referencia legitimadora de esta memoria, es decir, una tradición (Ibíd.: 142). Para poder hablar de religión se requiere, por tanto, que la invocación a la tradición que tiene lugar en el acto de creer encuentre su razón de ser última en la consideración del pasado como algo transcendente y sagrado. En este sentido, la religión, definida a partir de la invocación a la tradición, nos remite de forma directa a la memoria colectiva: "la posibilidad de que un grupo humano (o un individuo) se reconozca como parte de un linaje depende en efecto, al menos por una parte, de las referencias al pasado y de los recuerdos que tiene conciencia de compartir con otros y que se siente responsable de transmitir" (Ibíd.: 177).

Veamos a continuación de qué modo las diferentes definiciones de religión habilitan nuevos desarrollos teóricos que permiten repensar sus complejas relaciones con la identidad nacional. Los casos de Quebec y el País Vasco servirán de referente para mostrar la potencialidad del marco analítico propuesto ${ }^{2}$.

\section{LA RELIGIÓN COMO MARCADOR DE LA IDENTIDAD NACIONAL}

De forma inmediata, más allá de la reconstrucción de los objetos de estudio como fruto de rupturas epistemológicas, la relación entre identidad nacional y religión es evidente. Esta última, la religión de "sentido común" (cristianismo, judaísmo, islam. etc.), ha sido la que ha permitido conformar identidades nacionales que se definían, se "nombraban", a partir de aquella.

\footnotetext{
${ }^{2}$ Hay que dejar constancia de que la elección de los referentes de los nacionalismos vasco y quebequense no es consecuencia de un cierto "sentido común" o prejuicio, según el cual la etiqueta de nacionalismo se aplica exclusivamente a los de las llamadas naciones sin Estado, a los que también se les califica como étnicos o periféricos. Existe otro tipo de nacionalismo "banal", más propio de los Estados-nación consolidados, menos visible y más difuso, que solo se muestra como tal en determinadas ocasiones, ya que no tiene tanta necesidad de afirmarse (Billig, 1995). En este caso, dicha elección responde a una serie de criterios que derivan del marco analítico con el que se busca dar cuenta de las relaciones entre identidad nacional y religión. Para un análisis más profundo sobre la relación entre religión y nacionalismo aplicado a los casos de Quebec y el País Vasco, ver: Santiago, 2015.
} 
No obstante, es necesario distinguir entre las distintas grandes religiones, pues no todas han contribuido por igual al origen y desarrollo de las identidades nacionales. En este sentido es significativo comparar el islam con el cristianismo. Si seguimos a Hastings, "la nación y el nacionalismo son (...) caracteristicamente cristianos $y$, siempre que han aparecido en otras partes, lo han hecho dentro de un proceso de occidentalización y de imitación del mundo cristiano, incluso si ha sido imitado en su calidad de occidental y no de cristiano" (2000: 230). Por su parte, Smith (2000), el autor que más interés ha mostrado en las raíces religiosas de las identidades nacionales, matiza las tesis de Hastings señalando que, aunque teológicamente puede tener razón, sin embargo, históricamente el concepto universal de umma no ha imposibilitado la aparición de versiones étnicas y nacionales del islam. Ciertamente, a la hora de dar cuenta de la influencia de las diferentes religiones históricas en la formación de identidades nacionales, hay que tener presente que el condicionamiento de los postulados teológicos no determina inexorablemente dicha formación. No obstante, si prestamos atención a ciertas "imágenes religiosas del mundo" en sentido weberiano, es preciso señalar que la idea de una divinidad que elige a un pueblo coadyuvó al surgimiento de las identidades nacionales. En este sentido, el cristianismo ha posibilitado la conformación de éstas a través de los mitos de elección étnica, mediante los cuales los representantes de la etnia o nación se perciben a sí mismos como "instrumentos" de la divinidad (Smith, 2003). Ello les obliga a cumplir una misión religiosa que es al mismo tiempo cultural, y que descansa en la defensa y conservación de unos rasgos religiosos que marcan la comunidad nacional. Ya señaló Weber (1944) que la idea de nación lleva consigo la leyenda de una 'misión' providencial que debe realizarse mediante la conservación de los rasgos peculiares del 'grupo' considerado como la 'nación'.

En el origen de las identidades nacionales vasca y francocanadiense la religión jugó un papel decisivo en tanto que marcador que permitía "imaginar" la nación ${ }^{3}$. En el caso de Quebec, desde la llegada de los

\footnotetext{
${ }^{3}$ Para analizar la relación entre la identidad nacional y la religión en Quebec y el País Vasco y obtener los frutos que posibilitan la comparación, es necesario señalar que la aproximación que aquí se propone es de carácter "ahistórico", en un sentido similar, salvando las distancias, al de los estudios de sociología histórico-comparativa de Weber. Es decir, no se trata de mostrar las transformaciones de la identidad nacional con la riqueza de matices que nos podría proporcionar la historiografía. En lugar de privilegiar la
} 
colonos el catolicismo fue uno de los elementos fundamentales de la identidad nacional. Si bien, no fue hasta la aparición del llamado nacionalismo francocanadiense, que se desarrolló tras la Rebelión de los Patriotas (1837-1838), cuando la religión ocupó un lugar central. En ello fue clave la figura de Lionel Groulx, un sacerdote e historiador que ofreció la formulación más sistemática de la síntesis entre catolicismo y nacionalismo (Arès, 1968). Para este líder nacionalista, el alma de la identidad francocanadiense se hallaba en su catolicismo. En una América del Norte mayoritariamente protestante, entendía que el pueblo francocanadiense tenía la misión de hacer pervivir la fe católica: "Creemos suficientemente claras las indicaciones de la Providencia. El destino que ella nos ha marcado en América, el patrimonio que nos ha dejado, nos parecen dignos de ser salvaguardados a todo precio" (Groulx, citado en Ferretti y Miron, 1992: 94).

Sin el catolicismo la identidad nacional era inconcebible, ya que era su propia esencia y el principal rasgo diacrítico que permitía marcar la frontera del "nosotros nacional". Los otros rasgos que caracterizaban a los francocanadienses no eran tan determinantes. Así, la lengua, que a partir de la segunda mitad del siglo XX pasaría a ser el rasgo principal de la nueva definición nacional, no era para Groulx la "esencia" de la nación, sino únicamente su expresión. Aquella ejercía como guardiana de la fe: "(La lengua) misionera del Evangelio, guardiana del tipo francés, constituye para nuestro pueblo la principal garantía de su vida nacional y funda la esperanza cierta de la supervivencia del pueblo católico" (Groulx, citado en Senese, 1979: 168).

Al igual que en Quebec, en el País Vasco la identidad nacional vasca se conformó teniendo como principales referentes a la religión y a la raza. Tal y como lo formuló Sabino Arana, la pureza racial estaba estrechamente vinculada al integrismo religioso, convirtiéndose así el catolicismo en rasgo que delimitaba la identidad nacional. También él consideraba que el nacionalismo tenía que cumplir una misión de contenido religioso. En el caso del pueblo francocanadiense, esta misión consistía en la protección del catolicismo en una América del Norte mayoritariamente protestante. En el caso vasco, el catolicismo era defendido no porque corriera riesgo de ser asimilado por otra religión,

singularidad histórica, lo que se pretende es reconducir la complejidad del cambio histórico experimentado por la identidad nacional a un esquema típico-ideal que resulte significativo. 
sino para preservar su pureza ante la degradación que, según Arana, estaba sufriendo a manos de los "maketos". La forma en la que la misión religiosa se traducía en una misión nacional era clara:

\begin{abstract}
"Salvar a nuestros hermanos, proporcionándoles los medios adecuados para alcanzar su último fin: he ahí el único y verdadero del nacionalismo. Si, pues, éste trabaja por desarrollar nuestra lengua nacional, y por difundir el conocimiento de nuestra historia patria, sólo por ese fin trabaja: y aún la misma independencia (...) no tiene más valor que el de simple medio, si bien ya último y necesario, para el mismo fin (...) Bizcaya, dependiente de España, no puede dirigirse a Dios, no puede ser católica en la práctica" (Arana, citado en Corcuera, 2001: 350-352).
\end{abstract}

Del mismo modo que para el nacionalismo francocanadiense, en el caso vasco, la religión era un rasgo central, inalienable, de la identidad nacional. Y, al igual que en Quebec, también en el País Vasco el "nombre" de dicha identidad era inseparable de la religión. La nación no existía sin el catolicismo y éste no podía conservarse en su pureza a menos que se asumiera la causa nacional. El resto de rasgos diacríticos ocupaban un lugar secundario, en especial la lengua y el territorio. El euskera era un rasgo característico de la nación vasca, pero era valorado en tanto que servía para salvaguardar a los vascos de la degradación moral: "La única tabla de salvación que le queda aún al vasco (...) para hacer frente a la inmensa ola de corrupción, de blasfemias, de ideas sectarias y costumbres perversas (...) es sin duda, nuestro precioso, culto y eufónico idioma, el euzkera" (sacerdote anónimo cercano a Arana, citado en Corcuera, 2001: 353). Al igual que para el nacionalismo francocanadiense, la lengua era en última instancia guardiana de la fe y de la raza, pero no tenía valor en sí misma. No era un rasgo que definiera por sí solo la identidad nacional.

El hecho de que la identidad nacional se conformase, tanto en Quebec como en el País Vasco, a partir del catolicismo permitió que la Iglesia católica cumpliese un papel clave en su desarrollo. Éste es un aspecto fundamental para las naciones que no tienen Estado, pues no cuentan con estructuras institucionales que "objetiven" la identidad nacional y permitan su mantenimiento y desarrollo. En el caso de Quebec, el papel de la Iglesia ha sido evidente en el desarrollo de dicha identidad, al proteger los rasgos sobre los que se construía. Por esta razón se ha señalado que esta Iglesia tiene una fuerte tradición propiamente 
nacionalista (Bourgeault, 1978: 189). Desde la llegada de los colonos franceses, la Iglesia local contribuyó a la expansión de los rasgos característicos de la que posteriormente sería la nación francófona de Norteamérica. No obstante, no fue hasta La Conquista inglesa en 1760 que la Iglesia se fundió con el pueblo canadiense, pues hasta esa fecha nos encontramos propiamente hablando con una Iglesia francesa en tierra de la Nueva Francia (Ibíd.: 190). Fue la marcha de las elites francesas a la Madre Patria tras la victoria de los ingleses la que ocasionó un vacío de liderazgo que fue asumido por la Iglesia canadiense.

A diferencia de Quebec, el País Vasco no tuvo una religión que permitiese conformar una identidad nacional singular, lo cual pudo restar cierta implicación de la Iglesia católica en el desarrollo de la misma. Uno de los ideólogos de ETA, Krutwig, lo señalaba así:

"El pueblo vasco, al tener el mismo credo religioso que sus vecinos, no tiene una barrera religiosa. Por esta misma razón no hay problema vasco en el ámbito religioso y la Jerarquía católica no se preocupa del pueblo vasco (...) No hay duda de que si el pueblo vasco hubiese sido católico y sus vecinos de otra creencia, la Iglesia católica se hubiese esforzado en la salvaguardia de las características nacionales. Por otra parte, si se hubiese tenido una religión nacional, como es el caso de los judios o de los armenios, ésta hubiese servido para la defensa de la etnia vasca" (citado en Sarrailh de Ihartza, 1973: 76).

Ciertamente, en lo que respecta a la identidad nacional vasca, la relación con la Iglesia católica no fue tan clara como en el caso de Quebec, debido a la falta de una religión que la singularizase. A pesar de ello, la Iglesia en el País Vasco ha desempeñado un papel central en el desarrollo de su identidad nacional como resultado de diversos avatares. En primer lugar, debido a que la lengua y cultura vascas se mantuvieron históricamente al amparo de la Iglesia (Pérez-Agote, 1984: 99). En segundo lugar, el fundamento religioso del nacionalismo sabiniano, que prescribía la subordinación de la política a la religión, hizo que éste fuera defendido por algunos clérigos vascos, aunque no por la alta jerarquía eclesiástica (García de Cortázar, 1988: 70-74). En tercer lugar, hay que señalar el papel de la Guerra Civil, que marcó un momento de inflexión en las relaciones entre la Iglesia y el nacionalismo vasco. Como es sabido, una parte del clero vasco tomó partido, junto con los nacionalistas, por el bando republicano, enfrentándose con ello a la jerarquía eclesiástica que se puso del lado de los nacionales. Por último, tras la Guerra Civil, la Iglesia jugó un papel 
decisivo en el mantenimiento y desarrollo de la identidad nacional, pues en ella la lengua y cultura vascas encontraron un lugar que se les negaba en la esfera pública (Pérez-Agote et al., 1993).

\section{LA SACRALIZACIÓN DE LA HISTORIA NACIONAL-(ISTA)}

El anterior apartado comenzaba señalando que la religión ha sido un marcador que ha permitido conformar identidades nacionales. Así sucedió en el nacionalismo tradicional vasco y francocanadiense, en los que dicha identidad era impensable sin el elemento del catolicismo. El "nombre" que marcaba esa identidad era indisociable del catolicismo: "Nosotros para Dios, Dios para Euskadi" o "Católicos por encima de todo" son un buen reflejo de ello. Esta importancia de la religión se mantuvo hasta los años sesenta y setenta, en los que diversos procesos de cambio social, como la secularización o el surgimiento de nuevas corrientes nacionalistas de izquierda, hicieron que la religión y la raza fueran rasgos cada vez menos plausibles como fijadores de la identidad nacional. Surge entonces la cuestión de cómo es posible mantener una identidad nacional cuando han cambiado los rasgos que la caracterizaban. Dicho en términos de las definiciones de religión a las que antes se hacía referencia, ¿cómo es plausible el mantenimiento de una comunidad de culto (en sentido durkheimiano) cuando la comunidad religiosa (en sentido weberiano) en la que descansaba pierde su plausibilidad ${ }^{4}$ ? En definitiva, ¿cómo es posible mantener una identidad nacional de la que son partícipes distintas generaciones que se han identificado con la nación a partir de rasgos culturales que no sólo pueden tener poco que ver entre ellos, sino que además resultan a menudo contradictorios? Al igual que cuando hablamos de identidad individual, nos tenemos que preguntar qué es lo que posibilita la permanencia en el tiempo de una nación. ¿Qué es lo que hace plausible que, a pesar de los cambios que pueda experimentar, siga siendo la misma nación?

La respuesta hay que buscarla en la sacralización de la historia que lleva a cabo el nacionalismo, mediante la cual se hace posible un imaginario de continuidad. Recordemos en este sentido la propuesta de HervieuLéger de concebir la religión como un dispositivo de sentido focalizado

\footnotetext{
${ }^{4}$ Para un análisis más detallado sobre las comunidades religiosas y las comunidades de culto, así como sobre sus relaciones, puede verse Casanova (2000: 71-75) y Santiago (2010). Sin duda, la obra de Bellah (1970) debe ocupar un lugar destacado en la teorización de la relación entre estos dos tipos de comunidades.
} 
en la invocación al pasado, en "la invención, la producción imaginaria del vínculo que, a través del tiempo, funda la adhesión religiosa de los miembros al grupo que forman y a las convicciones que los vinculan" (1993: 118). ¿Cómo consigue el nacionalismo esa producción imaginaria del vínculo a través del tiempo? Dicho de otro modo y de forma más general, ¿de qué herramientas se sirve el nacionalismo para "historizar" y afrontar las rupturas que amenazan el imaginario de continuidad que hace plausible la identidad nacional?

Anderson (1993) ha incidido en ello al analizar las condiciones sociohistóricas que hicieron posible "imaginar" la nación. Entre otras, una nueva aprehensión del tiempo. Un "tiempo nuevo" que descansa en "una idea del tiempo homogéneo, vacío, donde la simultaneidad es, por decirlo así, transversal, de tiempo cruzado, no marcada por la prefiguración y la realización, sino por la coincidencia temporal, y medida por el reloj y el calendario" (Ibíd.: 46). Pero, si bien es la nueva concepción de la temporalidad la que hace posible pensar la nación, ésta, una vez que puede ser "imaginada", se alimenta de otra temporalidad: "La idea de un organismo sociológico que se mueve periódicamente a través del tiempo homogéneo, vacío, es un ejemplo preciso de la idea de la nación, que se concibe también como una comunidad sólida que avanza sostenidamente de un lado a otro de la historia" (Ibíd.: 48). En resumen, una doble temporalidad es la que da lugar a la narración de la identidad nacional. Por un lado, el "tiempo nuevo" que posibilita imaginar la nación. Por otro lado, el "tiempo viejo" que hace posible presentar la nación como comunidad inmemorial, el tiempo del género épico. Retengamos, en palabras del propio Anderson, la relevancia de esta doble temporalidad como condición necesaria para la narración de la identidad nacional: "La conciencia de estar formando parte de un tiempo secular, serial con todo lo que esto implica de continuidad, y sin embargo de 'olvidar' la experiencia de esta continuidad (...) da lugar a la necesidad de una narración de 'identidad'" (Ibíd.: 285). Los nacionalismos, por tanto, han buscado conjurar el "tiempo nuevo" por medio de un "tiempo viejo", a partir del cual las naciones se representan a sí mismas como entidades que hunden sus raíces en un pasado lejano, casi inmemorial. En esa tarea de "historizar", el nacionalismo ha encontrado un elemento de importancia capital en las Edades de Oro, que permiten a las naciones remontarse a un pasado épico, primordial, haciendo de ellas "comunidades genuinas" que 
existen desde mucho tiempo antes de que el nacionalismo las "despertase de un sueño profundo".

En el caso vasco, esa mítica Edad de Oro del nacionalismo sabiniano se habría caracterizado por una lengua divina (el euskera), unas leyes basadas en la naturaleza (los Fueros), la independencia política, la igualdad en la común nobleza y la frontera racial que separaba a los vascos de otros pueblos. Esta edad dorada tenía como referente a la sociedad vasca del Antiguo Régimen, que era sacralizada por la religión católica y la mitología campesina (Aranzadi, 2000: 491). El "tiempo viejo" para el nacionalismo sabiniano es el tiempo que remite a una Edad de Oro de una comunidad singularizada por la raza y la religión, rasgos significativos que hacen plausible el imaginario de continuidad.

Pero, ¿qué sucede en el caso de Quebec donde la nación no puede retrotraerse a un pasado premoderno? "¿Cómo superar el impasse original que nace de la voluntad de atribuirse unas raíces antiguas en una colectividad que, por definición, se encuentra en una suerte de punto cero de la temporalidad? O dicho de otro modo: ¿cómo construir una memoria larga a partir de una historia corta?" (Bouchard, 2001: 34). Todas las naciones del nuevo mundo han tenido que dar una respuesta plausible a esta pregunta. En Quebec la búsqueda del "tiempo viejo" se aprecia de forma nítida en el nacionalismo de corte tradicional, representado por Groulx, quien entendía que la nación ya era una realidad en tiempos de La Nueva Francia, periodo que fue idealizado como una Edad de Oro que terminó de forma traumática por La Conquista británica. La nación francocanadiense se remitía así a un tiempo primordial, un tiempo mítico del imaginario nacional que alimentaba la idea de una misión de reconquista, que tenía en la religión católica y la tradición francesa sus principales argumentos. Esta tradición francesa permitía a la nación francocanadiense remitirse a un pasado aún más lejano y mítico, el de los ancestros fundadores de la nación. De este modo, la memoria nacional "hundía sus lejanas raíces en el pasado más que milenario de Francia, el país de los ancestros fundadores, en la gran madre-patria. Esta referencia aseguraba un precioso anclaje simbólico a la frágil nación" (Ibíd.: 118). El nacionalismo francocanadiense podía así remitirse a unos orígenes lejanos con los que la nación resolvía la cuestión de su novedad. En la concepción racial de la nación de Groulx se dejaba notar ese imaginario de continuidad: "El nacimiento de una raza en Canadá no implica de ningún modo la ruptura 
de esta raza nueva con su viejo pasado francés" (Groulx, citado en Bouchard, 2001: 119).

Llevando las propuestas de Anderson más lejos y adaptándolas a lo que interesa mostrar en este artículo, habría que decir que el nacionalismo debe conjurar no solo el "tiempo nuevo" que hizo plausible imaginar la nación, sino también el "tiempo nuevo" que inauguran las nuevas definiciones de la identidad nacional. Es decir, debe recrear un imaginario de continuidad, no ya sólo con respecto al lejano pasado nacional, sino también en lo que se refiere a la ruptura que lleva consigo el cambio en la frontera simbólica del "nosotros nacional". Digámoslo de forma más clara a propósito de la religión: ¿qué sucede cuando esta deja de ser un marcador de identidad nacional? ¿Cómo es posible mantener un imaginario de continuidad cuando se rompe con el rasgo que era consustancial a dicha identidad? ¿Cómo se mantiene la identidad cuando el "nombre" cambia? Lo explicaremos mejor de manera aplicada a los casos vasco y quebequense.

Recordemos que tanto para Arana como para Groulx el catolicismo era un valor constitutivo de la identidad nacional. Los otros rasgos, que estaban estrechamente ligados a la raza y la religión, eran un medio para preservar la nación, pero no su "esencia". Así sucedía especialmente con la lengua. Groulx la concebía como "misionera del Evangelio" y una firme esperanza de "la supervivencia del pueblo católico". Por su parte, Arana entendía que la conservación del euskera no tendría ningún valor si fuese acompañada de la desaparición de la raza vasca, ya que, si ésta se produjese, la patria vasca moriría con ella. De tal manera que el fundador del PNV llegó incluso a señalar que si los "maketos" aprendieran euskera, los bizkainos deberían hablar otra lengua (Arana, 1995: 301). Frente a la concepción racial-religiosa de la nación, en los años sesenta del siglo XX el "nuevo" nacionalismo tanto en Quebec como en el País Vasco pasa a considerar a la lengua como un rasgo esencial de la identidad nacional y rechaza como elementos definidores a la raza y la religión. Cabría entonces preguntarse: ¿qué une a un francocanadiense según la definición del nacionalismo tradicional con un quebequense definido por el "nuevo" nacionalismo? ¿Qué vincula a un vasco definido por las fronteras étnicas fijadas por Arana con un vasco conforme a la concepción del "nuevo" nacionalismo? Atendiendo a los rasgos diacríticos que delimitan la frontera del "nosotros nacional", ¿no se excluirían mutuamente, según esas definiciones, aquellos que se 
identifican o identificaban con la misma nación? Por concretar e incluso personificar esta cuestión, se podría afirmar que "si se aplicasen los criterios biológicos propuestos por Sabino Arana, que basa la pureza del linaje vasco en los apellidos, algunos de los hombres más influyentes de la ETA inicial, tales como Txillardegui (Álvarez Emparanza), Federico Krutwig Sagredo, y José María Benito del Valle, no serían 'vascos'" (Jáuregui, 1981: 135). Cabría también preguntarse cuál habría sido la opinión de Arana sobre esta nueva redefinición de la identidad nacional que rompía con la raza y la religión como elementos primordiales: ¿se sentiría partícipe de esta identidad nacional que dejaba en un lugar secundario los componentes racial y religioso? ¿Hasta qué punto comparten la misma identidad nacional los francocanadienses, para los cuales la religión y el modo de vida rural eran los rasgos inalienables de la misma, y los quebequenses, que han roto con estos rasgos como marcadores del "nosotros nacional"? Como vemos, el "tiempo nuevo" que inaugura la nueva definición de la identidad nacional problematiza la temporalidad en la que el nacionalismo inscribe la nación. ¿Sigue el nacionalismo apelando al mismo "tiempo viejo" del nacionalismo tradicional o la nueva definición de la identidad nacional inaugura una nueva temporalidad?

En el caso vasco, la nueva definición nacional rompía con el nacionalismo tradicional, tanto con los rasgos que determinaban la identidad nacional como con su idealizada Edad de Oro. Ésta, que, como acabamos de ver, se remontaba al Antiguo Régimen, iba siendo "profanada" a medida que la historiografía mostraba el carácter poco idílico de ese periodo. Junto a ello, la crítica a la jerarquía eclesiástica y al catolicismo como rasgo primordial de la nación ponían las bases para la recreación de una nueva Edad de Oro. Recordemos las palabras de Krutwig cuando afirmaba que "debido a la tardía cristianización se not(a) entre los vascos una cierta tendencia a la religión natural, habiendo llegado a afirmar ciertos etnólogos que los vascos son sólo aparentemente cristianos" (Sarrailh de Ihartza, 1973: 76). Esta religión pagana, que se conservaría como consecuencia de la supuesta tardía cristianización del País Vasco, hundiría sus raíces en la Prehistoria, periodo que pasa a ser considerado como la nueva Edad de Oro (Aranzadi, 2000).

La cuestión de la temporalidad en la que el "nuevo" nacionalismo inscribe a la nación es más compleja en Quebec, ya que el nacionalismo 
quebequense representa a ésta como "nueva". En efecto, con la Revolución tranquila se inaugura una etapa de ruptura política con la que se quiere superar un pasado que se considera negativo para el desarrollo de la colectividad francófona. Un cambio que afecta a todos los ámbitos de la sociedad y también a la propia definición de la identidad nacional. Esta ruptura con el pasado se refleja de forma categórica en el cambio de "nombre" de la nación, que pasa de denominarse "francocanadiense" a "quebequense". Un cambio que supone una ruptura con el nacionalismo tradicional, para el que la identidad nacional se definía en términos raciales y religiosos. El "nuevo" nacionalismo concibe así una "nueva" nación, creada por el "Estado" de la provincia de Quebec y acotada a dicho territorio. Pero, ¿es la nación quebequense, "creada" por el "Estado", realmente nueva? ¿Se representa el "nuevo" nacionalismo a la nación quebequense como una entidad distinta a la nación francocanadiense? Los cambios en las fronteras que marcan el "nosotros nacional" nos indican que la nación quebequense ha roto en buena medida con la adscripción étnica de la nación francocanadiense y en ese sentido nos encontramos ante una nueva entidad de corte territorial e inclusivo. Sin embargo, aunque el nacionalismo quebequense se representa a la nación como nueva, ésta aparece como un eslabón más de un largo continuum histórico. La "nueva" definición de la identidad nacional conjura así el "tiempo nuevo" apelando a un imaginario de continuidad nacional. Para mostrarlo resulta significativo observar de qué manera se refería el programa del Parti Québécois de 1991 a la nación: "Canadienses del siglo XVII, Francocanadienses del siglo XIX y ahora Quebequenses, raramente se ha visto a un pueblo buscar tan largamente su identidad, $y$, por tanto, asumir lo esencial con tanta persistencia" (citado en Ferretti y Miron, 1992: 300). El Parti Québécois apela a la persistencia de un pueblo que a lo largo de la historia ha luchado por su identidad. No obstante, el propio cambio de nombre, la propia denominación de canadienses, francocanadienses y quebequenses parecen remitirnos a identidades diferentes.

\section{LA SACRALIZACIÓN DEL TERRITORIO}

La sacralización de la historia es uno de los dispositivos decisivos de los que se sirve el nacionalismo para conjurar el "tiempo nuevo" y hacer plausible así la permanencia de la identidad nacional a pesar de las 
transformaciones que experimenta. En la producción de este imaginario de continuidad un elemento desempeña un papel capital: el territorio. Su importancia radica en que es el recipiente que hace plausible que la identidad nacional se mantenga a pesar de los cambios. Como ha señalado Anderson, "el territorio es el receptáculo del pasado en el presente" (1988: 24). Permite la vertebración temporal de la nación: "el tiempo ha pasado pero el espacio permanece ahi" (Ibíd.), haciendo así posible la ilusión de continuidad. Como afirma Smith:

\begin{abstract}
"para crear una nación hace falta un territorio histórico al cual apreciar y defender y cuya 'propiedad' sea reconocida por propios y extraños. Esto es esencial para cualquier ideología del nacionalismo. De ahí se sigue que una parte importante de todo concepto de identidad 'nacional' estribe en el proceso de señalar, deslindar y reinterpretar una tierra natal auténtica que una a los ancestros con las personas vivientes y a los que están aún por nacer" (1998: 64).
\end{abstract}

La estrecha relación entre la identidad nacional y el territorio es el fruto de la moderna matriz espacial, propia del sistema de Estados, que está en el origen de los nacionalismos y de las identidades nacionales. Como bien vio Poulantzas:
"las fronteras y el territorio nacional no son previos a la unificación de lo que encuadran: no hay al principio algo que está dentro y que hay que unificar después (...) El Estado establece las fronteras de este espacio serial en el curso mismo de la acción con la que unifica y homogeneiza lo que esas fronteras encierran. Así es como este territorio se hace nacional, tiende a confundirse con el Estado-nación, y como la nación moderna tiende a coincidir con el Estado" (1979: 125).

Dicho de otro modo, tal y como señala Farinelli (Lladó, 2013), el mapa precede al territorio, al que el Estado impone las características del modelo geométrico euclidiano (continuidad, homogeneidad eisotropismo), generando así las identidades nacionales.

El nacionalismo, como "ideología" hija del Estado, necesita, por tanto, "territorializar" la identidad nacional, sacralizar el territorio. Un territorio que no es:

"únicamente (...) un hábitat natural donde se asienta una comunidad, (...) una simple área geográfica más o menos delimitada, sino (...) un territorio 'histórico', único, distintivo, con una identidad ligada a la memoria y una memoria ligada a 
la tierra. La historia nacionaliza un trozo de tierra e imbuye de contenido mítico y de sentimientos sagrados a sus elementos más característicos. El territorio se convierte así en el receptáculo de una conciencia compartida colectivamente" (Nogué, 1998: 74).

Mucho se habla de la importancia que tiene la memoria colectiva para la construcción de la identidad nacional. Renan fue pionero en señalar esta relación al afirmar que "la esencia de una nación está en que todos los individuos tengan muchas cosas en común y también que todos hayan olvidado muchas cosas" (citado en Anderson, 1993: 23). Sin embargo, no se ha profundizado suficientemente en el hecho de que la memoria colectiva nacional se conforma con respecto a un determinado territorio. Es lo que Smith ha calificado como la territorialización de la memoria. El nacionalismo persigue que nunca se olvide que la tierra, la patria - homeland-, ha sido "suya" generación tras generación (1996: 454). Halbwachs ya señaló que la memoria colectiva sólo es plausible en referencia a un grupo concreto: "no hay memoria universal. Toda memoria colectiva tiene como sostén un grupo delimitado en el espacio y en el tiempo" (1950: 75). En efecto, la territorialización de la memoria sólo cobra sentido en función de un determinado grupo que se apropia simbólicamente de un territorio que considera de su propiedad. Una reapropiación que se lleva a cabo en la memoria colectiva asegurándose un eco, ya que, como señalaba Desroche, "el eco en la memoria colectiva y el viático -o prevención- en la conciencia colectiva se combinan también entre sí para resistir las pérdidas de activación y aceleración de la esperanza, nacida -in illo tempore- en los sagrados lugares de la imaginación colectiva" (1976: 41). Se crean así las "condiciones de una memoria que se vincula con ciertos lugares y contribuye a reforzar su carácter sagrado" (Augé, 1995: 65).

Se vinculan de este modo los dos componentes que caracterizan a la nación: los origenes y la tierra natal. El nacionalismo se sirve de toda una serie de metáforas arborescentes y de parentesco para llevar a cabo su gran tarea ideológica: "enfatizar la unidad entre territorio e historia" (Anderson, 1988: 18). La recurrencia de este tipo de metáforas, especialmente las de las raíces arborescentes, en el discurso y la simbología nacionalista, sugiere la existencia de una cultura transnacional del nacionalismo. Cultura arborescente, fuertemente arraigada, mediante la cual el nacionalismo se apropia del espacio y del tiempo. Malkki (1992) ha mostrado las consecuencias de esta cultura 
que vincula estrechamente nación y territorio y que representa a ésta como algo que existe en y por la tierra. La más inmediata es la territorialización de la identidad, que se evidencia, de nuevo, en la terminología con la que se habla de la nación: raíces, soil, fatherland, motherland, autóctono o en la lista de los nombres de los países con sufijo en land (Ibíd.). Esta vinculación entre identidad nacional y territorio nos coloca a las puertas de la sacralización de la nación, pues "situar a la comunidad en una tierra natal antigua y abigarrada (...) es fundamental para evocar las peculiaridades primordiales $y$ transcendentales de la nación" (Smith, 1998: 64).

El territorio se constituye así en el soporte último de la identidad nacional. Lo que interesa mostrar en este momento es que, como fruto de este proceso de territorialización de la identidad nacional, ésta se piensa metonímicamente por referencia al territorio. Dicho de otro modo, el territorio de los ancestros es el que permite rememorar el pasado y hacer plausible la continuidad entre las generaciones. La identidad nacional se mantiene en el tiempo en y por el territorio. En efecto, gracias a él se logra la narración de la identidad nacional, ya que los orígenes comunes, ligados en el nacionalismo tradicional a la idea de raza, pueden ser pensados de forma metonímica por referencia al territorio cuando aquel rasgo pierde peso específico en la determinación de la identidad nacional (Cabrera, 1992: 148).

Un buen ejemplo de ello lo encontramos tanto en el nacionalismo vasco como en el quebequés. En ambos casos, el territorio ha ido adquiriendo una creciente importancia en la identidad nacional. Recordemos a este respecto las palabras de Arana:
“¿Es acaso la tierra que pisamos lo que constituye la patria? ¿Qué más nos da tener una Bizcaya libre aquí entre estas montañas, como tenerla en otra parte? Solamente nos importaría esto lo que a aquél que al trasladarse de domicilio, se ve precisado a dejar la casa en que naciera y se criara; y tan poco nos importaría a nosotros aquello como a éste le importara su traslado, con tal que lo hiciese acompañado de su familia" (Arana, 1995: 147).

Y continúa: "Una Bizcaya que supongas en estas montañas desprovista de alguno de los caracteres de ese lema - Jaun-goikua eta Lagi-zarraya no es Bizcaya. Por el contrario: una sola legua cuadrada de cualquier parte del mundo, donde se establezcan algunas familias con ese lema, 
eso es Bizcaya" (Ibíd.: 222). Frente a ello, el "nuevo" nacionalismo vasco considera el territorio, no como un elemento accesorio de la identidad nacional, sino como un elemento inalienable de la misma. Así sucede especialmente en el caso de la izquierda abertzale, para la cual "la territorialidad, noción que expresa el derecho de la nación vasca al territorio formado por los siete herrialdes históricos, se constituye por tanto en elemento simbólico de creación de identidad y de diferencialidad" (Martínez, 1999: 41).

De igual forma, en Quebec el territorio ha pasado de ser un elemento secundario en la identidad nacional a devenir central. Para el nacionalismo tradicional, la nación francocanadiense se extendía más allá de las fronteras del territorio de Quebec. En efecto, en el siglo XIX y tras la derrota de Los Patriotas, el territorio de Quebec estaba circunscrito al valle del río San Lorenzo. No obstante, el crecimiento demográfico provocó una expansión hacia el Este y el Oeste, tomando así razón de ser una idea de la nación pancanadiense, que encontraría una confirmación institucional en 1867 con el Acta que creaba la confederación canadiense. Sin embargo, esta representación del territorio fue puesta en entredicho cuando el gobierno central suprimió los derechos de los francocanadienses en el exterior de Quebec y favoreció la inmigración europea con el fin de poblar los territorios del Oeste, poniendo así fin al modelo de dualidad nacional de Canadá. Tras ello, la conciencia nacional se replegaba sobre sus antiguas bases espaciales, apropiándose simbólicamente del territorio del valle del río San Lorenzo, considerado como la patria de los francocanadienses. No obstante, la concepción de un pueblo francocanadiense que desborda las fronteras de Quebec es una constante que sólo cambia en la segunda mitad del pasado siglo. Con la nueva definición de la identidad nacional que trae consigo el "nuevo" nacionalismo, el Canadá francés deviene un Quebec francófono. La nación se repliega y de su estatuto pancanadiense retorna a su viejo asentamiento en el Bajo Canadá, rompiendo así con la referencia canadiense. Con esta operación los francocanadienses de Quebec pasaban del estatuto de minorías a escala canadiense a ser mayoritarios a escala quebequense. De este modo, el territorio devenía uno de los referentes principales de la identidad nacional quebequense (Helly y Van Schendel, 1996).

En definitiva, tanto en el nacionalismo vasco como en el quebequense la sacralización del territorio se hace aún más acuciante debido 
precisamente a la transformación de la identidad nacional, desde el nacionalismo étnico, que primaba la raza y la religión, a un nacionalismo en el que el territorio, además de ser componente necesario e imprescindible de la soberanía política, pasa a ser una significativa seña de identidad desde la que se legitima dicha soberanía.

\section{CONCLUSIÓN}

La diversidad de formas de concebir tanto la identidad nacional como la religión se presta a que el análisis de la relación entre ellas pueda orientarse por diferentes caminos. En este trabajo se ha propuesto un marco de análisis sobre el papel que desempeña la religión en el origen y mantenimiento de dicha identidad nacional, entendiendo que este último concepto hace referencia a un proceso, entre otros, por el cual resulta plausible que una nación, a pesar de los cambios que pueda experimentar a lo largo de la historia, siga siendo la misma nación. Para analizar el papel que la religión desempeña en este proceso se ha problematizado la propia categoría de religión partiendo para ello de algunas de sus definiciones y rupturas epistemológicas. Con el objetivo de mostrar sus potencialidades, el marco analítico se ha aplicado al País Vasco y Quebec. En ambos casos hemos visto de qué modo la religión histórica o de "sentido común" desempeñó un papel decisivo en el origen de las identidades nacionales vasca y francocanadiense. De igual forma se ha analizado cómo dichas identidades nacionales se mantuvieron a pesar de la pérdida de sus rasgos tradicionales, permitiendo así la conformación de comunidades de culto en sentido durkheimiano. Para ello resultó decisiva la participación de la religión, si la concebimos en esta ocasión, a la luz de la ruptura epistemológica propuesta por Hervieu-Léger, como categoría que, a través de la invocación al pasado, posibilita la conformación de un imaginario de continuidad. En este artículo se ha examinado el papel que desempeña el nacionalismo para hacer plausible dicho imaginario de continuidad. Dos son las operaciones que aquel lleva a cabo para conseguir tal fin. Por un lado, la sacralización de la historia, que permite dotar de continuidad a la identidad nacional a pesar de las transformaciones que haya podido experimentar. Por otro lado, la sacralización del territorio, en tanto que receptáculo y soporte último de dicha identidad. 


\section{Bibliografía}

Anderson, B. (1993). Comunidades imaginadas. Reflexiones sobre el origen y la difusión del nacionalismo. México: Fondo de Cultura Económica.

Anderson, J. (1988). Nationalist ideology and territory. In R. Johnston, D. Knight \& E. Kofman (Eds.), Nationalism, Self-Determination and Political Geography (pp. 18-39). London: Groom Helm.

Arana, S. (1995). La patria de los vascos. Antología de escritos políticos. San Sebastián: R\&B (Edición de A. Elorza).

Aranzadi, J. (2000). Milenarismo Vasco. Edad de oro, etnia y nativismo. Madrid: Taurus.

Arès, S. J. (1968).Catholicisme et nationalisme en une synthèse vivante. L'action nationale, 57(10), 936-947.

Augé, M. (1995). Los no lugares. Una antropología de la sobre modernidad. Barcelona: Gedisa.

Bellah, R. N. (1970). Civil Religion in America. In R. Bellah, Beyond Belief: Essays on Religion in a Post-Traditional World (pp. 168-189). New York: Harper \& Row.

Billig, M. (1995). Banal nationalism. London: Sage.

Bouchard, G. (2001). Genèse des nations et cultures du Nouveau Monde. Essai d'histoire comparée. Montréal: Bóreal.

Bourgeault, G. (1978). Le nationalisme québécois et l'église. Canadian Review of Studies in Nationalism/Revue canadienne des études sur le nationalisme, 2, 189-207.

Cabrera, J. (1992). La nación como discurso. Madrid: Centro de Investigaciones Sociológicas.

Caillois, R. (1982). El viento del invierno. In D. Hollier (Ed.), El Colegio de Sociología (pp. 51-65).Madrid: Taurus.

Casanova, J. (2000). Religiones públicas en el mundo moderno. Madrid: PPC.

Corcuera, J. (2001). La patria de los vascos. Orígenes, ideología y organización del nacionalismo vasco. Madrid: Taurus.

Desroche, H. (1976). Sociología de la esperanza. Barcelona: Herder.

Dobbelaere, K. (2008). La secularización: teoría e investigación. In A. Pérez-Agote $\&$ J. Santiago (Eds.), Religión y política en la sociedad 
actual (pp. 17-34). Madrid: Editorial Complutense-Centro de Investigaciones Sociológicas.

Dubar, C. (2002). La crisis de las identidades. Barcelona: Bellaterra.

Durkheim, E. (1982). Las formas elementales de la vida religiosa. Madrid: Akal.

Ferretti, A. \& Miron, G. (Eds.) (1992). Les grands textes indépendantistes. Écrits, discours et manifestes québécois 1774-1992. Montréal: L'Hexagone.

García de Cortázar, F. (1988). Iglesia vasca, religión y nacionalismo en el siglo XX. In F. García de Cortázar \& J. P. Fusi, Política, nacionalidad e Iglesia en el País Vasco (pp. 59-114). San Sebastián: Txertoa.

Gatti, G. (2007). Identidades débiles. Una propuesta teórica aplicada al estudio de la identidad en el País Vasco. Madrid: Centro de Investigaciones Sociológicas.

Guibernau, M. (2004). Anthony D. Smith on nations and national identity: a critical assessment. Nations and Nationalism, 10(1/2), 125-141.

Halbwachs, M. (1950). La mémoire collective. Paris: PUF.

Hastings, A. (2000). La construcción de las nacionalidades. Etnicidad, religión y nacionalismo. Madrid: Cambridge University Press.

Helly, D. \& Van Schendel, N. (1996). Variations identitaires sur la nation. Tradition, territoire et langue. In M. Elbaz, A. Fortin \& G. Laforest, (Eds.), Les frontières de l'identité. Modernité et postmodernisme au Québec (pp. 206-218). Sainte-Foy/Paris: Les Presses de l'Université Laval/L'Harmattan.

Hervieu-Léger, D. (1993). La religion pour mémoire. Paris: Les Éditions du Cerf.

Jáuregui, G. (1981). Ideología y estrategia política de ETA. Análisis de su evolución entre 1959 y 1968. Madrid: Siglo XXI.

Kaufmann, J.C. (2015). Identidades. Barcelona: Ariel.

Lladó, B. (2013). Franco Farinelli. Del mapa al laberinto. Barcelona: Icaria.

Maffesoli, M. (1990). El tiempo de las tribus. Barcelona: Icaria.

Malesevic, S. (2011). The chimera of national identity. Nations and Nationalism, 17(2), 272-290.

Malkki, L. (1992). National Geographic: The Rooting of Peoples and the Territorialization of National Identity Among Scholars and Refugees. Cultural Anthropology, 7(1), 24-44. 
Martínez, J. (1999). La construcción nacional de Euskal Herria. Etnicidad, política y religión. Donostia: Tarttalo.

Martuccelli, D. (2007). Gramáticas del individuo. Buenos Aires: Losada.

Nogué, J. (1998). Nacionalismo y territorio. Lleida: Milenio.

Pérez-Agote, A. (1984). La reproducción del nacionalismo. El caso vasco. Madrid: Centro de Investigaciones Sociológicas.

Pérez-Agote, A. (1986). La identidad colectiva: una reflexión abierta desde la sociología. Revista de Occidente, 56, 76-90.

Pérez-Agote, A. et al. (1993).Religión, política y sociedad en el País Vasco. In R. Díaz-Salazar \& S. Giner (Eds.), Religión y sociedad en España (pp. 243-281). Madrid: Centro de Investigaciones Sociológicas.

Poulantzas, N. (1979). Estado, poder y socialismo. Madrid: Siglo XXI.

Santiago, J. (2010). Comunidad y religión. Comunidades religiosas y cultos de la comunidad política. In P. de Marinis, G. Gatti \& I. Irazuzta (Eds.), La comunidad como pretexto. En torno al (re)surgimiento de las solidaridades comunitarias (pp. 413-436). Barcelona: Anthropos.

Santiago, J. (2015). Siete lecciones de sociología de la religión y del nacionalismo. Barcelona: Anthropos.

Sarrailh de Ihartza, F. (1973). Vasconia. Buenos Aires: Norbait.

Senese, P. M. (1979). Catholique d'abord!: Catholicism and nationalism in the thought of Lionel Groulx. Canadian Historical Review, 60, 154177.

Smith, A. D. (1991). National Identity. Reno: University of Nevada Press.

Smith, A. D. (1996). Culture, community and territory: the politics of ethnicity and nationalism. International Affairs, 72(3),445-458.

Smith, A. D. (1998). Conmemorando a los muertos, inspirando a los vivos. Mapas, recuerdos y moralejas en la recreación de las identidades nacionales. Revista Mexicana de Sociología, 60(1),61-80.

Smith, A. D. (2000). The sacred dimension of nationalism. Millennium. Journal of International Studies, 29(3), 791-814.

Smith, A. D. (2003). Chosen Peoples. Oxford: Oxford University Press.

Weber, M. (1944). Economía y sociedad. México: Fondo de Cultura Económica. 